\title{
Treatment Of Gingival Recession By Free Gingival Autograft : Two Cases Report
}

\author{
Dr. Raju Anarthe ${ }^{1}$, Dr. Ameet Mani ${ }^{2}$, Dr. P.P. Marawar ${ }^{3}$ \\ 1-Sr. Lecturer, 2-Reader, 3-Professor and Head \\ Dept. of Periodontology, Rural Dental College, Pravara Institute of Medical Sciences, Loni- 413736 \\ Maharashtra State, India
}

\begin{abstract}
Gingival recession is defined as "Displacement of soft tissue margin apical to the cemento-enamel junction". Gingival recessions require treatment for many reasons - impaired aesthetic appearance, root sensitivity, cervical caries or abrasion. Presence of gingival recession and gingival inflammation in areas with a lack or narrow band of attached gingiva is identified as a mucogingival problem. Periodontal plastic surgery procedures are performed to resolve these mucogingival problems. According to Miller, root coverage procedure is quite predictable and produces patient satisfaction. Present paper presents two cases of class I gingival recession (Miller's Classification) successfully treated with complete root coverage by free gingival autograft. Free gingival graft proved more effective and seems to be a promising treatment modality with the benefit of more stable results for class I gingival recession.
\end{abstract}

Key words: Gingival recession, root sensitivity, root coverage, mucogingival surgery, free gingival autograft $(F G G)$.

\section{Introduction}

Gingival recession is defined as displacement of gingival margin from the cementoenamel junction. The major causes of gingival recessions are genetically determined morphologic peculiarity, improper oral hygiene and periodontal disease [1]. Various clinical studies have evaluated many surgical techniques for root coverage: rotational flaps, advanced flaps, free gingival grafts, connective tissue grafts, guided tissue regeneration and combination of these procedures [2]. Free gingival grafting is a well established pure mucogingival procedure for increasing the width of attached gingiva. The procedure has proven reliable in increasing attached gingiva and stopping the progressive gingival recession.

\section{Case Presentation}

\subsection{CASE 1.}

A 30 years old female patient reported to the department of Periodontology, Rural Dental College and Hospital, Loni, Maharashtra (India) with a chief complaint of sensitivity of a tooth and root exposure in mandibular front region (Fig. 1.). Her general health condition was good, did not take any medications, had no known allergies and was nonsmoker. Intraorally periodontal examination revealed the gingival recession of 4 $\mathrm{mm}$ in height. The patient's oral hygiene was fair. There was no other periodontal concern other than Miller's class II recession of tooth \#41. Presurgical therapy included patient motivation, education, plaque control instruction, scaling, root planing and after 3 weeks of re-evaluation the lower incisor showed apico-coronary $5 \mathrm{~mm}$ of recession, mesio-distally $3 \mathrm{~mm}$ of recession due to shrinkage of gingiva after non surgical treatment. After the patient's consent, it was decided to treat the site by Miller's technique for free autogenous gingival grafting to achieve root coverage and simultaneously increase the attached gingiva.

\subsection{CASE 2.}

A 39 years old female patient reported to the department of Periodontology, Rural Dental College and Hospital , Loni, Maharashtra (India) with a chief complaint of root surface exposure and sensitivity in mandibular front region (Fig. 7.). Her systemic health condition was good, she was not under any medications, had no known allergies and was nonsmoker. Intraorally periodontal examination revealed the gingival recession of $5 \mathrm{~mm}$. The patient's oral hygiene was fair. There was no other periodontal concern other than Miller's class III recession of tooth \#41. Presurgical therapy included patient motivation, education, non surgical periodontal therapy and after 3 weeks of re-evaluation the lower incisor showed apico-coronary $6 \mathrm{~mm}$ of recession, mesiodistally $3 \mathrm{~mm}$ of recession. After the patient's consent, it was decided to treat the site by Miller's technique for free autogenous gingival grafting to achieve root coverage and simultaneously increase the attached gingiva. 


\section{Surgical Procedure \\ 3.1. PREPARATION OF RECIPIENT SITE}

After local anesthesia and intraoral disinfection with $0.2 \%$ chlorhexidine mouthrinse , the exposed root surfaces were planed thoroughly with a Gracey 1-2 curette in both the cases. The horizontal incision was made at the level of cemento-enamel junction extending from the line angle of adjacent teeth on either side of the recession deep into the papilla, creating a well defined butt joint. At the distal terminal of the horizontal incision, vertical incision was given extending well into the alveolar mucosa. A partial thickness flap was elevated and excised apically (Fig. 2. and Fig. 8 ) followed by root biomodification by tetracycline hydrochloride $50 \mathrm{mg} / \mathrm{ml}$ for 3 minutes.

\subsection{PREPARATION OF DONOR TISSUE}

The amount of donor tissue needed was accurately determined by using a foil template. The right side of palate between first and second premolar which had greater thickness was selected to harvest the donor tissue. The initial incision was outlined by the placement of tinfoil template with a number 15 scalpel blade. A bevel access incision was made to get an even thickness of the graft. The incision was made along the occlusal aspect of the palate with number 15 scalpel blade held parallel to the tissue, continued apically, lifting and separating the graft. The graft was placed on the recipient bed and sutured by means of interrupted sutures (4-0 Vicryl resorbable) at the coronal and apical borders (Fig.5 and Fig. 10)

\subsection{POST OPERATIVE INSTRUCTIONS}

The patient was prescribed amoxicillin 500mg, 400mg of ibuprofen thrice daily for 5 days and instructed to rinse twice daily with $0.2 \%$ chlorhexidine rinse for 6 weeks postoperatively. Surgical site was irrigated with normal saline and sutures were removed 10 days after surgery, home care instructions were given. The healing of palatal wound was satisfactory; patient did not complain of any discomfort. The patient was instructed to use a ultra soft tooth brush with a roll technique. The case was evaluated after every 15 days for follow up. Figure 6 shows complete healing of free gingival autograft 6 months postoperative.

\section{Discussion}

Gingival recession usually creates an aesthetical problem and fear of tooth loss due to progressing destruction, and it may also be associated with dentine hypersensitivity and/or root caries, and cervical wear (3).

Coverage of denuded roots has become one of the most challenging procedures in periodontal mucogingival surgery. Various surgical options have been developed to achieve the root coverage and include the use of FGGs, subepithelial connective tissue graft, laterally sliding flap, coronally advanced flap, double papilla flap, guided tissue regeneration [4].

The literature on FGGs reports very different results with percentages of root coverage ranging from $11 \%$ to $100 \%$ [5]. These differences may be attributed to differences in the severity of gingival recessions and in surgical techniques. The successful root coverage with FGG was obtained ranging from 90 to $100 \%$ in class 1 and 2 gingival recession. The presence of a wide band of keratinized gingiva was known to provide better plaque control, which leads to a possible significant improvement of the periodontal attachment apparatus.

Root coverage by placing free graft was first described by Sullivan and Atkins, they reported that free gingival graft offer best results in cases of shallow and narrow recession [6]. According to them when graft is placed over recession, some amount of "bridging" can be expected because a portion of grafted tissue which is covering the root will survive by receiving circulation from the vascular portion of the recipient site. In addition to bridging, creeping attachment can result in a post operative coronal migration of free gingival margin [6].

Miller in 1987 has proposed many factors for incomplete or failure of root coverage. These include improper classification of marginal tissue recession, inadequate root planing, improper root biomodification, improper preparation of recipient site, inadequate graft size and thickness, dehydration of graft, inadequate adaptation of graft to root and remaining periosteal bed, failure to stabilize the graft, excess or prolonged pressure in captions of sutured graft, reduction of inflammation prior to grafting, trauma to graft during initial healing [7].

\section{Conclusion}

According to Miller, root coverage procedure is quite predictable and produces patient satisfaction; it should be therapist's obligation to make patients aware of this treatment modality. Autogenous free gingival grafting is a well established pure mucogingival procedure for increasing the width of attached gingiva. The surgical procedure is technique sensitive and attention to the details involved in the execution of the surgery is crucial to achieve a successful and satisfying outcome. 


\section{References}

[1]. Chr. Popova, Tsv. Boyarova,Two-step Surgical Procedure for Root Coverage (Free Gingival Graft and Coronally positioned Flap) , Journal of IMAB - Annual Proceeding 2007.

[2]. Tugnait A., Clerehugh V,Gingival recession - its significance and management, Journal of Dentistry Vol.29, 2001, 381-394

[3]. Alparslan Dilsiz1, Tugba Aydin, Gingival Recession Associated with Orthodontic Treatment and Root Coverage, Journal of Clinical Experimental Denistry 2(1):2010; 30.

[4]. Wennström J, Mucogingival therapy, Annals of Peridontology, 1(1, 1996, 671.

[5]. Miller PD Jr, Regenerative and reconstructive periodontal plastic surgery, Dental Clinics of North America, 32, 1988, 287-306

[6]. Sullivan H, Atkins J, Free autogenous gingival grafts-Utilization of grafts in the treatment of gingival recession, Periodontics 6(4), $1968 ; 152$.

[7]. Miller Jr P. Root coverage with the free gingival graft-Factors associated with incomplete coverage, Journal of Periodontology $58(10), 1987,674$.

\section{CASE 1.}

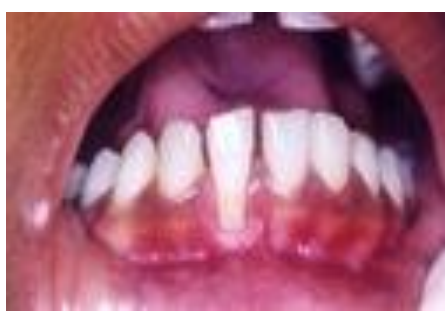

fig. 1. class i gingival recession

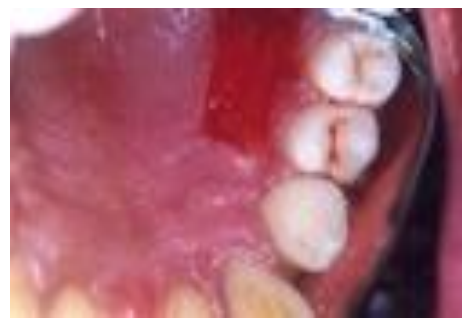

fig. 3. free gingival graft harvested from palate

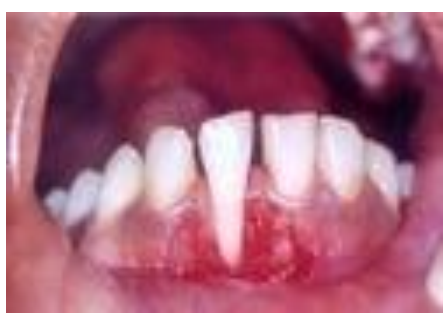

fig. 2. preparation of the receipient area

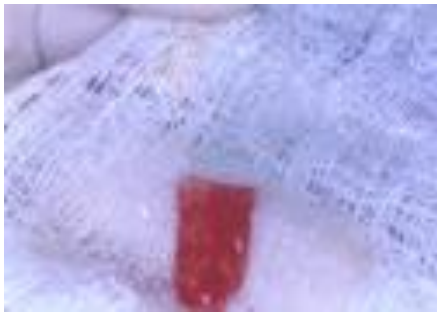

fig. 4. free gingival graft

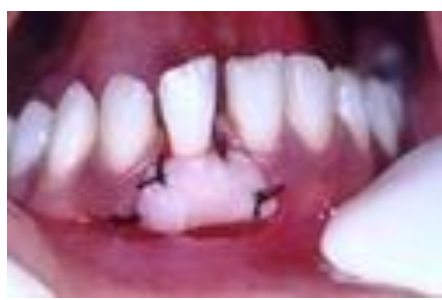

fig. 5. free gingival graft sutured.

\section{CASE 2.}

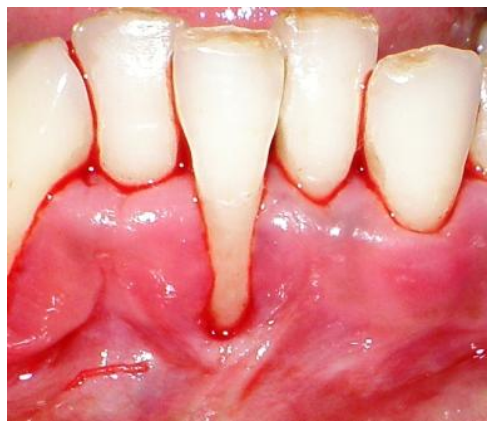

fig. 7. class iii gingival recession

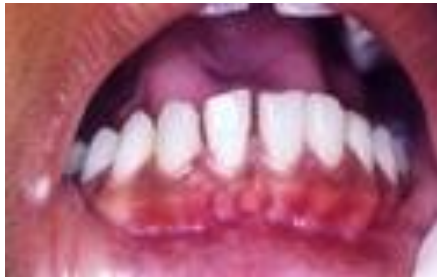

fig 6. postoperative view (3 months)

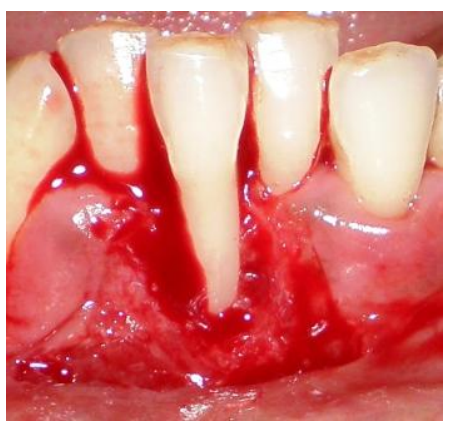

fig 8. preparation of the receipient area 


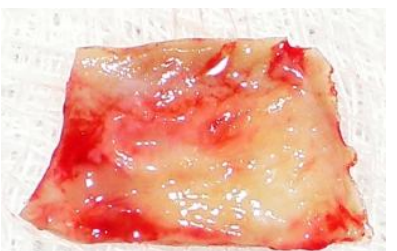

fig. 9. free gingival graft harvested from palate

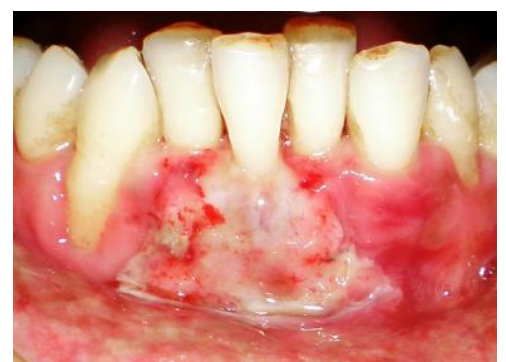

fig. 11. postoperative view (2 months)

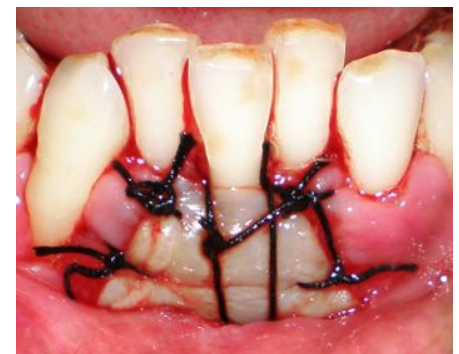

fig. 10. free gingival graft sutured.

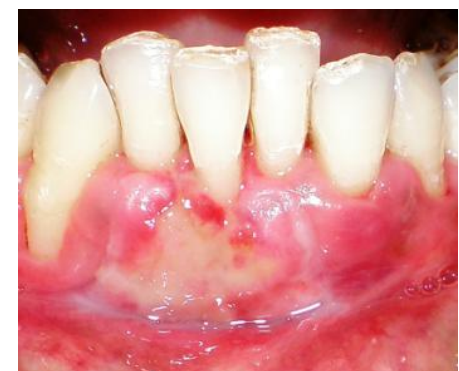

fig 12. postoperative view (6 months) 